\title{
Aspects regarding the surface roughness on a steel part cutted using AWJ technology
}

\author{
Adrian-Paul Basarman ${ }^{1, *}$ and Mircea Lobonțiu ${ }^{1}$ \\ ${ }^{1}$ Technical University of Cluj Napoca, North University Center from Baia Mare, Dr. Victor Babeș \\ Street 62A, 430083, Baia Mare, Romania.
}

\begin{abstract}
The abrasive water jet cutting technology is a new and modern technology which uses an abrasive material carried by water at high pressure to pierce and cut a desired material. It is a technology used to cut a high variety of materials, from rocks to glass, metal or even human tissue. Regarding the metal cutting using AWJ technology, the surface roughness is a very important aspect when it comes to surface quality and precision. This paper presents a series of aspects regarding the surface roughness on a C45 steel part cutted using AWJ technology, presenting the variation of the surface roughness and the aspect resulted after cutting, on the surface of the cut.
\end{abstract}

\section{Introduction}

The abrasive water jet cutting technology is a new and modern technology which uses an abrasive material carried by water at high pressure to pierce and cut a desired material. This paper presents a series of aspects regarding the surface roughness on a C45 steel part cutted using AWJ technology, presenting the variation of the surface roughness and the aspect resulted after cutting, on the surface of the cut. The abrasive water jet cutting technology is continuously researched by different authors like Srivastava et. al [1], Popan et. al. [2,3], Ravai Nagy et.al. [4], Vusal et. al. [5] and Herghelegiu et. al. [6].

The quality of the cutted surfaces and also precision are the key elements regarding the study and the research of cutting of the metal parts using abrasive water jet.

For better analyzing and in order to make a connection between the AWJ cutting parameters and the aspect/quality of the cutted surface, a series of roughness measurements were taken in different areas of the cutted surface, divided in three rows that represent three different areas (Primary impact zone, smooth zone and rough zone) [7]. For studying the zones in which the surface deviations are different on the height of the cutted surface, a series of macroscopic analyzes were made at different magnification powers.

A paper regarding the analyzing of the surface roughness of the parts cutted using AWJ cutting technology was done by authors [8] and the current paper is a continuation of the same research.

In the present paper it will be analyzed a single surface cutted using the parameters presented in table 1.

\footnotetext{
${ }^{*}$ Corresponding author: adrian.basarman@cunbm.utcluj.ro
} 
Table 1. Cutting parameters.

\begin{tabular}{|c|c|}
\hline Parameters & Selected value \\
\hline Breakthrough time & $13 \mathrm{~s}$ \\
\hline Breakthrough pressure & $3600 \mathrm{bar}$ \\
\hline Abrasive material used & $\begin{array}{c}\text { GMA Garnet } 80 \text { Mesh } \\
(300-150 \mathrm{micron})\end{array}$ \\
\hline Quantity of abrasive material & $342 \mathrm{~g} / \mathrm{min}$ \\
\hline Cutting pressure & $3600 \mathrm{bar}$ \\
\hline Cutting speed & $45 \mathrm{~mm} / \mathrm{min}$ \\
\hline Interior sapphire nozzle & $0.28 \mathrm{~mm}$ \\
\hline Exterior nozzle & $0.8 \mathrm{~mm}$ \\
\hline
\end{tabular}

\subsection{Abrasive water jet cutting machine}

Research has been made using the AWJ cutting machine presented in figure 1a) and the part presented in figure 2a) resulted after extracting it from the plate presented in figure $1 b$ ).

a)
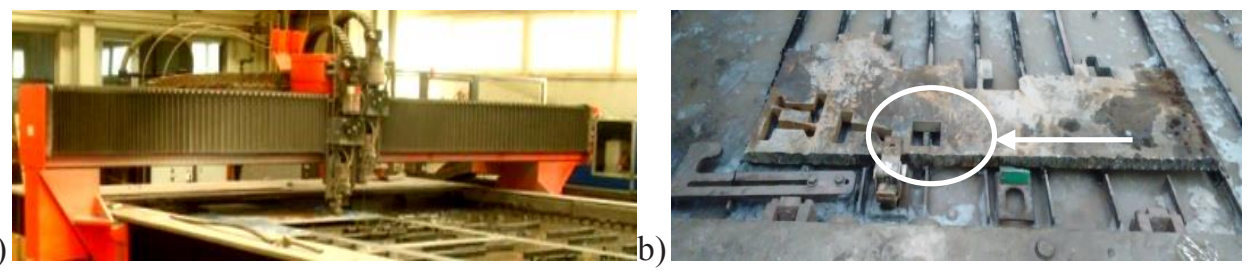

Fig. 1. a) AWJ cutting machine -Bystronic ByJet Pro L-, b) the plate from which the part was cutted.

\subsection{Measuring the roughness of the surface cutted using AWJ}

The cutted surface was divided in 9 zones, as one can see in figure 2 a). The roughness of the surface was measured using a TR200 roughness tester, as presented in figure $2 \mathrm{~b}$ ).

a)

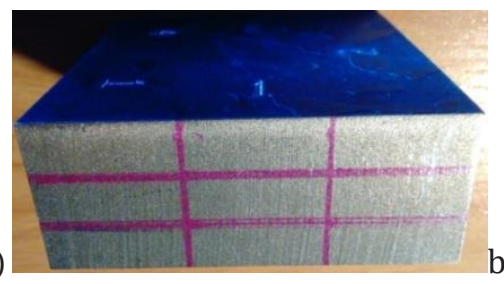

b)

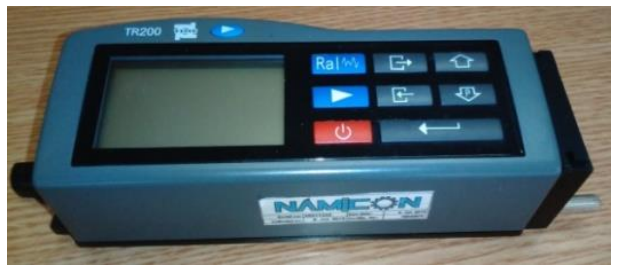

Fig. 2. a) Dividing the surface of the cutted part for measuring, b) TR200 roughness tester.

The dividing was made in such way in order to capture the 3 distinct zones [4] as presented in figure 3 .

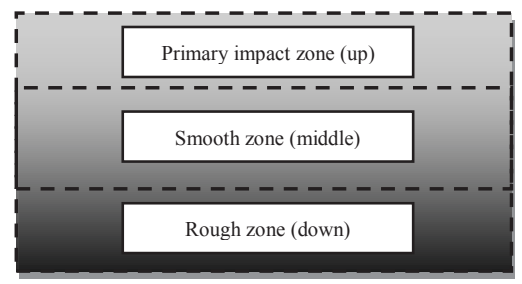

Fig. 3. The zones resulted on an abrasive water jet cutted metal surface. 
For better analyzing and understanding of the obtained data, every zone as presented in figure 3 is divided in 3 , as seen in figure 2 a) in order to have a number of 3 measurements on every zone. In this way results a number of 9 zones which are numbered as in table 2 .

Table 2. Setting and encoding the 9 zones.

\begin{tabular}{|c|c|c|c|}
\hline $\begin{array}{c}\text { Measurements column } \\
\text { Measurement zones }\end{array}$ & M1 & M2 & M3 \\
\hline UZ (up zone) & UZM1 & UZM2 & UZM3 \\
\hline MZ (middle zone) & MZM1 & MZM2 & MZM3 \\
\hline DZ (down zone) & DZM1 & DZM2 & DZM3 \\
\hline
\end{tabular}

\subsection{Macroscopic analyzing of the surface cutted using abrasive water jet}

For start, the surface was cleaned using a solvent that removes the grease applied previously on the surface for anticorrosive protection purpose. That lubricating film makes it impossible to correctly visualize the surface under a microscope.

After removing the lubricating film an optic microscope was used for visualizing the surface and two light sources to prevent the shadowing of surface and assuring a better medium for capturing the images, as it can be seen in figure 4 a) and b).

a)

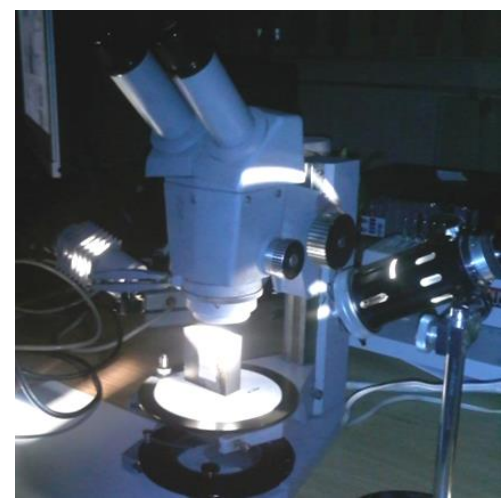

b)

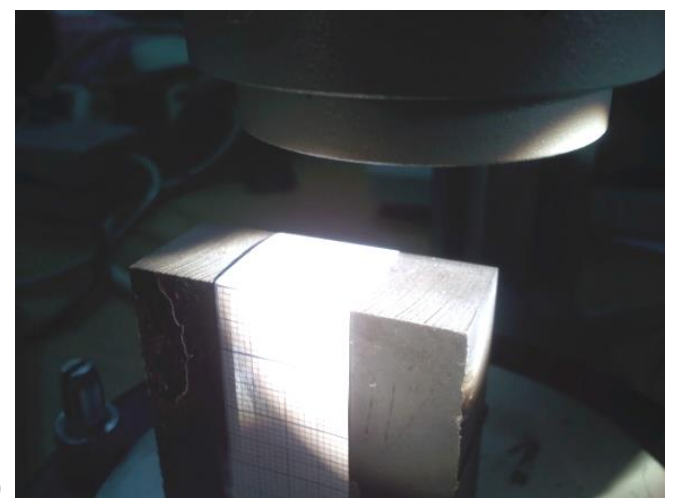

Fig. 4. The system used for doing the research regarding the surface macrostructure: a) the microscope and the two light sources, b) the metal part analyzed [ C45 50x50×20 mm].

To ease the recording and data processing, and also as method for measuring the surface, on the surface that was studied was attached a piece of millimeter paper, as seen in figure 5 .

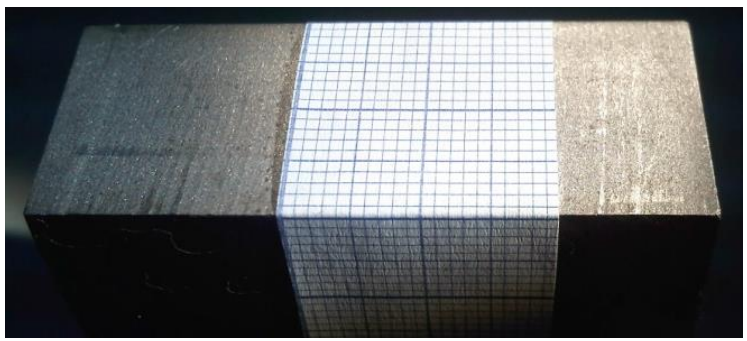

Fig. 5. The millimeter paper attached on the AWJ cutted surface. 


\section{The roughness measurements results}

All the measured values are presented in table 3.

Table 3. The measured values corresponded for each of the 9 zones, for both Ra and Rz.

\begin{tabular}{|c|c|c|c|c|c|c|c|c|}
\hline Measurement & \multicolumn{2}{|c|}{ M1 } & \multicolumn{2}{c|}{ M2 } & \multicolumn{2}{c|}{ M3 } & \multicolumn{2}{c|}{ Average } \\
\hline Zone & $\begin{array}{c}\text { Ra } \\
{[\mu \mathrm{m}]}\end{array}$ & $\begin{array}{c}\mathbf{R z} \\
{[\mu \mathrm{m}]}\end{array}$ & $\begin{array}{c}\mathbf{R a} \\
{[\mu \mathrm{m}]}\end{array}$ & $\begin{array}{c}\mathbf{R z} \\
{[\mu \mathrm{m}]}\end{array}$ & $\begin{array}{c}\mathbf{R a} \\
{[\mu \mathrm{m}]}\end{array}$ & $\begin{array}{c}\mathbf{R z} \\
{[\mu \mathrm{m}]}\end{array}$ & $\begin{array}{c}\mathbf{R a} \\
{[\mu \mathrm{m}]}\end{array}$ & $\begin{array}{c}\mathbf{R z} \\
{[\mu \mathrm{m}]}\end{array}$ \\
\hline $\mathbf{U Z}$ & 2.597 & 16.59 & 3.089 & 18.84 & 2.889 & 16.78 & 2.858 & 17.403 \\
\hline $\mathbf{M Z}$ & 2.831 & 14.64 & 3.06 & 17.54 & 2.873 & 16.8 & 2.903 & $16 . .327$ \\
\hline $\mathbf{D Z}$ & 4.105 & 20.04 & 3.527 & 18.87 & 3.247 & 16.7 & 3.626 & 18.537 \\
\hline
\end{tabular}

For visualizing and a better understanding of the aspect of asperities present on the surface cut using the abrasive water jet cutting technology and, with the help of the roughness tester, was done also a surface profilogram measurement for every zone analyzed.

These profilograms were grouped on measurements so that they can be observed better and, in figures 6, 7 and 8 are presented on columns, the three measurements (M1, M2 and M3), according to tables 2 and 3.

Every figure presents each a set of three profilograms of the surface, the positioning depending of the zone analyzed (UZ, MZ, DZ).

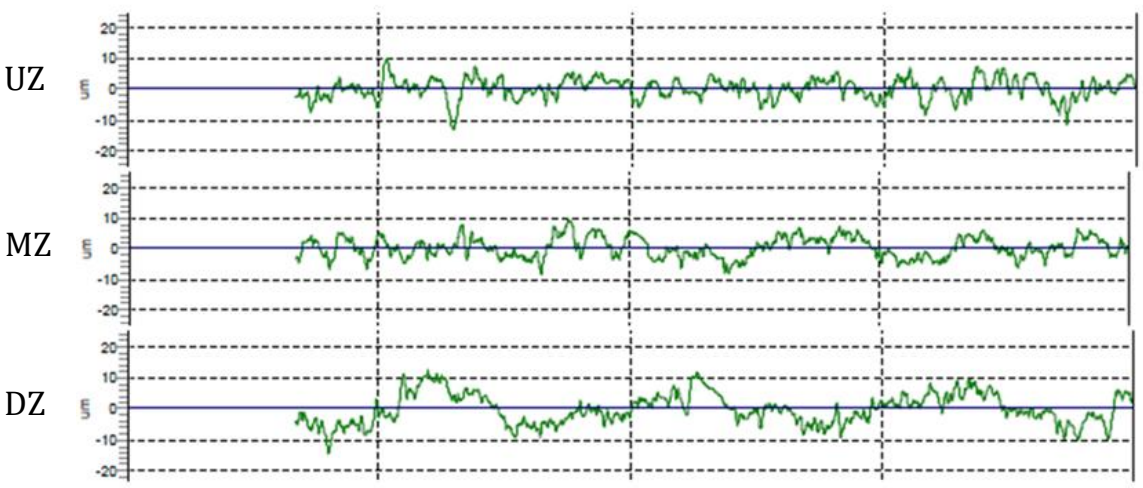

Fig. 6. Profilogram of the measurement M1. 
$\mathrm{UZ}$

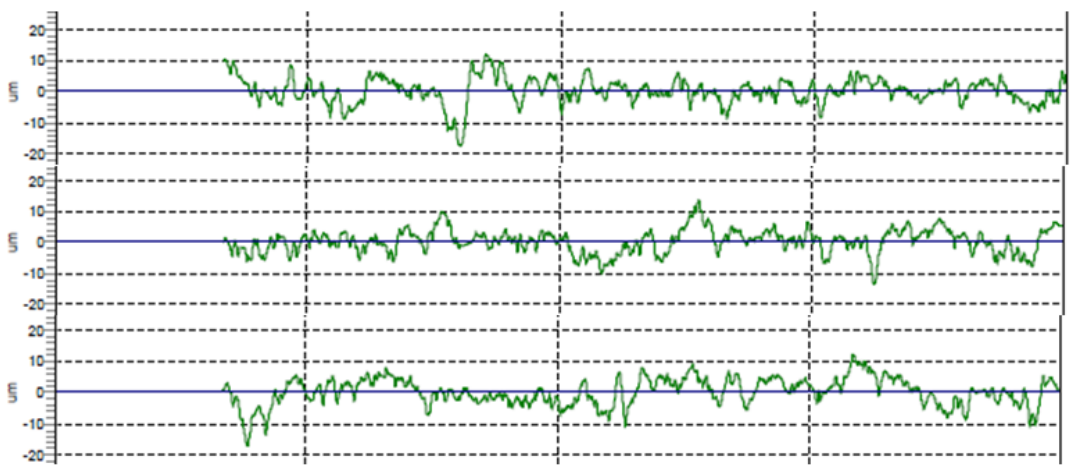

Fig. 7. Profilogram of the measurement M2.

UZ

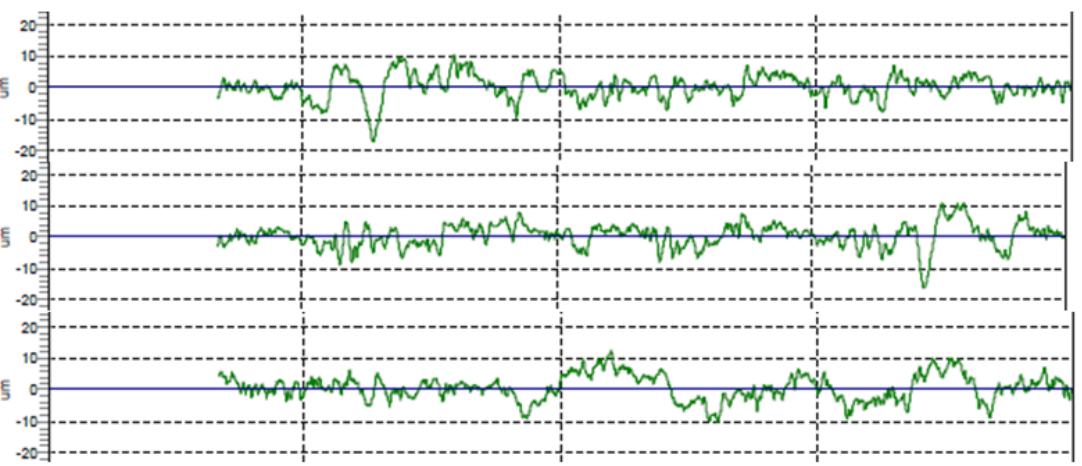

Fig. 8. Profilogram of the measurement M3.

\section{The macroscopic analyzing results}

For a better analyzing of the abrasive water jet cutted surface, using the optical microscope, the surface was photographed at a magnification power of 10 times bigger and respectively, at a magnification power of 80 times bigger.

Every picture taken were grouped to form a film of the entire surface so, in this case, in the figure 9 is presented, starting from an isometric view of the analyzed surface, from the part cutted using abrasive water jet technology, to a surface 10 times bigger and finally, followed by an 80 times magnification of the same surface.

On the left of each presented surfaces can be seen the millimeter paper which helps for measuring the depth of the zones with different asperities.

After analyzing the surface from figure 9, the depth of each zone with different asperities, as explained in figure 3, were measured and the results can be seen in table 4 .

Table 4. The depth of each zone on the AWJ cutted surface.

\begin{tabular}{|c|c|}
\hline Measurement zone & Approximated value [mm] \\
\hline UZ (up zone) & 5 \\
\hline MZ (middle zone) & 7 \\
\hline DZ (down zone) & 8 \\
\hline
\end{tabular}




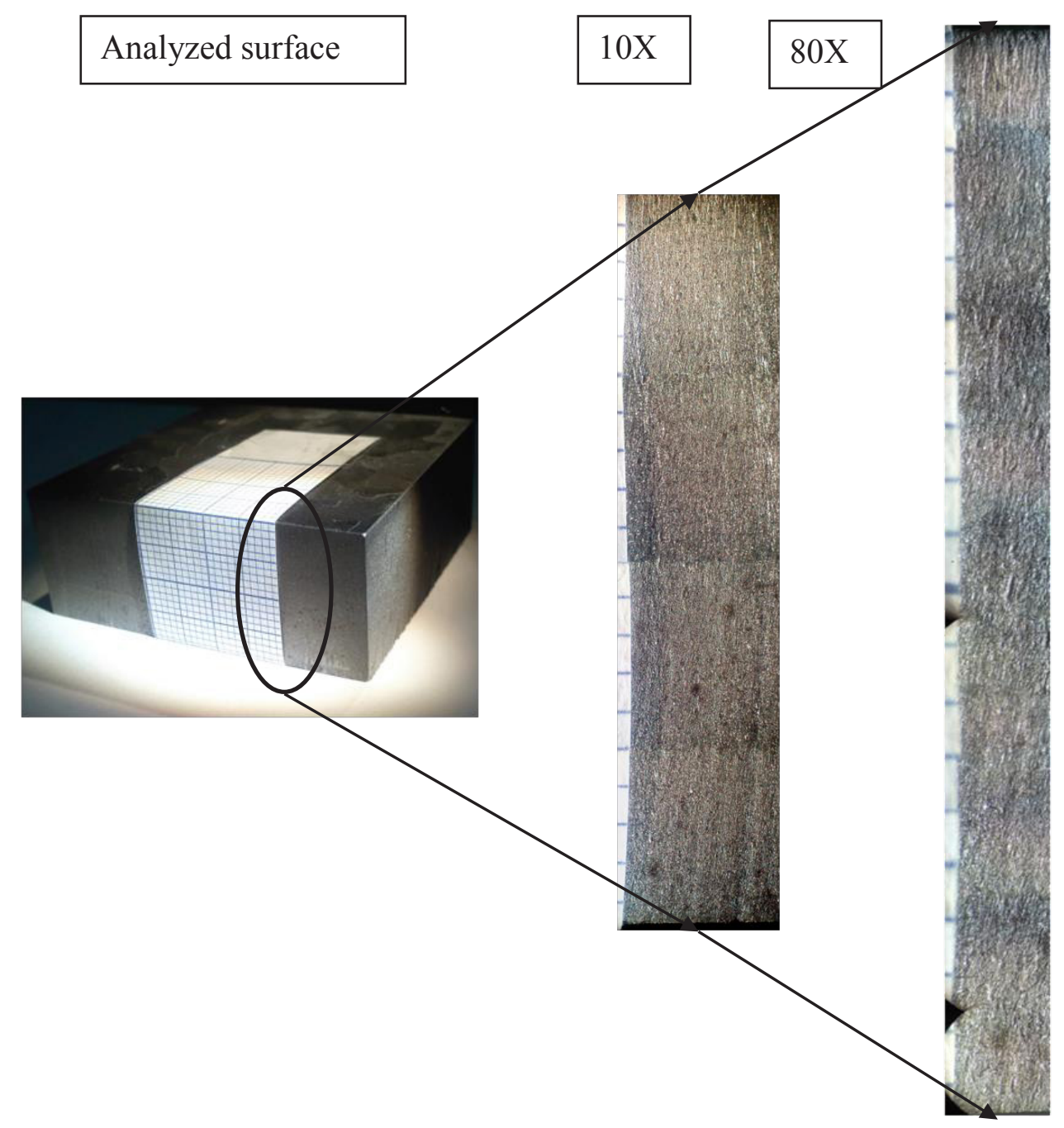

Fig. 9. The macrostructure of the surface cutted using the AWJ cutting technology.

Description of the zones: UZ is the zone from the top part of the analyzed surface which presents the lowest value of the measured roughness; MZ is the middle zone of the metal part where the surface presents a roughness a bit bigger than in the UZ zone but, smaller values that in the DZ zone; and, the DZ zone is the bottom area of the AWJ cutted surface which presents the biggest values for roughness and is the zone with the most surface irregularities.

\section{Conclusions}

After analyzing the research and results, a series of conclusions emerged:

1) The surface cutted using AWJ cutting technology has asperities with different dimensions in different zones of the surface resulted from cutting. 
2) The surface cutted using the AWJ cutting technology presents 3 distinct zones (UZ, MZ, DZ) which present an increasing of the roughness of the surface, from up to down.

3) The depth of the zones is at $5 \mathrm{~mm}$ for UZ, $7 \mathrm{~mm}$ for MZ and $8 \mathrm{~mm}$ for DZ, on a $20 \mathrm{~mm}$ C45 metal part cutted using AWJ cutting technology.

4) Ra roughness recorded for the 3 zones has a min of 2,597 $\mu \mathrm{m}$ in UZM1, 3,006 $\mu \mathrm{m}$ in the middle zone MZM2 and the maximum of $4,105 \mu \mathrm{m}$ in DZM1.

5) For the first $5 \mathrm{~mm}$ of the cut the surface has a $2,858 \mu \mathrm{m}$ Ra roughness, for the next $7 \mathrm{~mm}$ a 2,903 $\mu \mathrm{m}$ Ra roughness and for the last $8 \mathrm{~mm}$ has a 3,626 $\mu \mathrm{m}$ Ra roughness.

6) The surface presents and increasing of roughness from top to bottom, as one can observe also from the visual aspect of the part, seen in the images from figure 9.

\section{References}

1. A.K. Srivastava, A. Nag, A.R. Dixit, S. Tiwari, et al., J. Manuf. Process 28, 11-20 (2017)

2. A. Popan, N. Bâlc, A. Carean, A. Luca, et al. Applied Mechanics and Materials. Trans Tech Publ 760, 409-414 (2015)

3. A. Popan, N. Bâlc, I. Popan, MATEC Web of Conferences. EDP Sciences, 121, 02010 (2017)

4. S. Ravai-Nagy, N. Medan, Hidraulica, 4, 12-17 (2016).

5. B. Vusal, M. Gunel. An Investigation on the Suitability of Abrasive Waterjet Cutting for Hybrid Manufacturing of Gears in Automotive Industry, Master of Science Thesis in master program: Production Engineering and Management in the Department of Production Engineering, Royal Institute of Technology, (2015)

6. E. Herghelegiu, M.C. Radu, C. Schnakovszky, C.N. Tampu, MATEC Web of Conferences. EDP Sciences, 94, 03007 (2017)

7. J. Valíček, S. Hloch, D. Kozak Study of surface topography created by abrasive waterjet cutting. Slavonski Brod: Strojarski fakultet u Slavonskom Brodu Sveučilišta J.J. Strossmayera u Osijeku, ISBN 978-953-6048-48-9, (2011)

8. A.P. Basarman, M. Lobonțiu, N. Medan, Scientific Bulletin, Series C: Fascicle Mechanics, Tribology, Machine Manufacturing Technology 30, 10-16 (2016). 
